\title{
Effects of Residual Stress on Hydrogen Embrittlement of a Stretch-Formed Tempered Martensitic Steel Sheet
}

\author{
Hayato NISHIMURA, ${ }^{1,2)}$ Tomohiko HOJO, ${ }^{1) *}$ Saya AJITO, ${ }^{1)}$ Yuki SHIBAYAMA, ${ }^{1,3)}$ Motomichi KOYAMA, ${ }^{1)}$ \\ Hiroyuki SAITOH, ${ }^{4)}$ Ayumi SHIRO, ${ }^{4)}$ Ryo YASUDA, ${ }^{4)}$ Takahisa SHOBU ${ }^{5)}$ and Eiji AKIYAMA ${ }^{1)}$ \\ 1) Institute for Materials Research, Tohoku University, 2-1-1 Katahira, Aoba-ku, Sendai, 980-8577 Japan. \\ 2) School of Engineering, Tohoku University, 6-6-01-2 Aramaki Aza Aoba, Aoba-ku, Sendai, 980-8579 Japan. \\ 3) Graduate School of Engineering, Tohoku University, 6-6-01-2 Aramaki Aza Aoba, Aoba-ku, Sendai, 980-8579 Japan. \\ 4) National Institutes for Quantum and Radiological Science and Technology (QST), 1-1-1 Kouto, Sayo, Hyogo, $679-5148$ Japan. \\ 5) Japan Atomic Energy Agency (JAEA), 1-1-1, Kouto, Sayo, Hyogo, 679-5148 Japan.
}

(Received on August 11, 2020; accepted on September 24, 2020; J-STAGE Advance published date: December 4, 2020)

\begin{abstract}
The effects of residual stress on the hydrogen embrittlement behavior of a tempered martensitic steel sheet with 1-GPa-class tensile strength stretch-formed by a hemisphere punch simulating press-formed automotive structural parts were investigated. Cracking on the stretch-formed specimen induced by potentiostatic hydrogen charging was initiated in the foot of the impression of the specimen and propagated to the radial direction both toward the hillside and the plain. The mixture of quasi cleavage and intergranular fractures were observed whole through the fracture surface. Residual stress in the stretch-formed specimens was analyzed by using energy-dispersive X-ray diffraction method utilizing the synchrotron X-ray radiation at SPring-8. In addition, stress and plastic strain distributions in the specimen were analyzed by using Finite Element Method (FEM). These analyses depicted that the high tensile stress in the circumferential direction was in the foot of the impression, corresponding to the direction of the crack growth. The FEM analysis revealed that the high triaxial stress was in the foot suggesting accumulation of hydrogen. It was considered that the preferential crack initiation at the foot was promoted by the high residual stress in the circumferential direction and the hydrogen accumulation due to stress-induced diffusion.
\end{abstract}

KEY WORDS: high strength steel; hydrogen embrittlement; press forming; residual stress; plastic strain; energy-dispersive $\mathrm{X}$-ray diffraction method; finite element method.

\section{Introduction}

The automotive frame parts have been strengthened to improve the impact safety and to decrease vehicle weight for better fuel economy and reducing $\mathrm{CO}_{2}$ emissions. Recently, 980- and 1 180-MPa-grade high-strength steel sheets have been practically applied for the automobile parts; however, when tensile strength exceeds $980 \mathrm{MPa}$, hydrogen embrittlement becomes a critical issue. ${ }^{1,2)}$ There are some hydrogen embrittlement testing techniques to evaluate the susceptibility to hydrogen embrittlement, for instance, constant load test $(\mathrm{CLT}){ }^{3,4)}$ slow strain rate technique $(\mathrm{SSRT})^{5,6)}$ and conventional strain rate technique (CSRT).$^{7-10)}$ To assess the applicability of the high-strength steel sheets for automotive structural parts, hydrogen embrittlement properties of steels, such as ferrite-martensite Dual Phase (DP) steels, ${ }^{11-13)}$ low alloy Transformation-Induced Plasticity (TRIP)-aided

\footnotetext{
* Corresponding author: E-mail: hojo@imr.tohoku.ac.jp
}

steels ${ }^{14-18)}$ and tempered martensitic steels, ${ }^{19,20)}$ have been evaluated in previous studies using the above-mentioned techniques.

High-strength steel sheets are assembled to automotive frame parts after press-forming, so that residual stress and plastic strain are introduced by the press-forming and restraint stress is applied due to the assembling in the steel sheets. Therefore, it is necessary to consider the effects of them on hydrogen embrittlement property. There have been some reports about evaluation of the hydrogen embrittlement properties of high-strength steel sheets considering the effects of deformation. Toji et al. ${ }^{21)}$ have evaluated the hydrogen embrittlement properties of a DP steel using U-bend specimens employing immersion in $\mathrm{HCl}$ solutions of $\mathrm{pH} 1$ and 3 and drew a 3-dimensional fracture map considering factors of tensile stress, strain and hydrogen concentration. Yoshino et l. $^{22)}$ have investigated the influence of sheared edges of U-bend specimens on the hydrogen embrittlement properties and have reported the influence 
of an increase in stress intensity factor due to microcrack introduced on the edges by bending on fracture. Some of the authors of the present paper have proposed an evaluation method for hydrogen embrittlement of high-strength steel sheets using U-bend specimens. ${ }^{23)}$ In addition to U-bending, stretch-forming, deep-drawing and hole-expanding are widely used to evaluate the press-formabilities of steel sheets and these forming methods can be also utilized to evaluate hydrogen embrittlement property of formed steel sheets.

In this study, a specimen of a common tempered martensitic steel, with a tensile strength of about $1000 \mathrm{MPa}$, stretch-formed by using a hemispherical punch was adopted as a model of press-formed steel parts and its hydrogen embrittlement property was evaluated. Because formed steel sheets have complicated distributions of stress and strain, it is required to analyze them to understand their effects on hydrogen embrittlement. Hence, the stress distribution of the stretch-formed specimen was analyzed by means of X-ray Diffraction (XRD) method utilizing the synchrotron $\mathrm{X}$-ray radiation at BL14B1 in SPring-8. Since the synchrotron X-rays can penetrate steel sheets, its utilization has a significant advantage to measure the internal stress distribution. In conjunction with that, the stress and plastic strain distributions of the stretch-formed specimens were analyzed by using Finite Elemental Method (FEM). Using these analytical methods, the effects of the stress and plastic strain distributions on the hydrogen embrittlement property of the stretch-formed specimens of the conventional martensitic steel have been investigated in this study.

\section{Experimental Procedures}

Specimens used in this study were prepared from a commercial steel rod of SCM435 steel with a chemical composition of $0.35 \mathrm{C}-0.18 \mathrm{Si}-0.74 \mathrm{Mn}-0.0011 \mathrm{P}-0.0017 \mathrm{~S}-1.15 \mathrm{Cr}-0.15 \mathrm{Mo}$ (mass\%), which was $60 \mathrm{~mm}$ in diameter and $500 \mathrm{~mm}$ in length. The rod was annealed at $850^{\circ} \mathrm{C}$ for $2 \mathrm{~h}$ and subsequently quenched in oil. Then, the quenched sample was tempered at $530^{\circ} \mathrm{C}$ for $3 \mathrm{~h}$ to produce the tempered martensitic steel. The tensile strength of the steel obtained by using the tensile specimens with $10 \mathrm{~mm}$ in gauge length, $3 \mathrm{~mm}$ in width and $1.0 \mathrm{~mm}$ in thickness was $1023 \mathrm{MPa}$ in average as shown in Table 1. The tempered rod was sliced into disks with a thickness of $1 \mathrm{~mm}$ and both sides of the disks were mechanically and electrochemically polished.

Figure 1 shows the schematic view of the stretch-forming unit. This disk-shaped steel sheet was cut into $40 \mathrm{~mm} \times$ $40 \mathrm{~mm}$ and was stretch-formed using the unit. Graphite lubricant was sprayed on the steel sheet surface where the sheet was contacted with a hemispherical punch, and the steel sheet coated with the graphite lubricant was fixed in the stretch-forming jig. The steel sheet was stretch-formed

Table 1. Tensile properties of the tempered martensitic steel used in this study. YS: $0.2 \%$ proof stress, $T S$ : tensile strength, $U E l$ : uniform elongation, $T E l$ : total elongation.

\begin{tabular}{cccc}
\hline$Y S(\mathrm{MPa})$ & $T S(\mathrm{MPa})$ & $U E l(\%)$ & $T E l(\%)$ \\
\hline 718 & 1023 & 5.3 & 11.2 \\
\hline
\end{tabular}

by using the hemispherical punch with a radius of $8.5 \mathrm{~mm}$

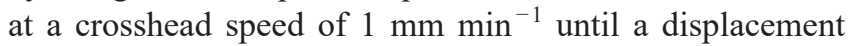
of $4.2 \mathrm{~mm}$ from the position where the punch and specimen were contacted.

Figure 2 shows the schematic view of the hydrogen embrittlement testing unit. Hydrogen charging was carried out by means of cathodic hydrogen charging in a $3 \mathrm{wt} \%$ $\mathrm{NaCl}+20 \mathrm{~g} \mathrm{~L}^{-1} \mathrm{NH}_{4} \mathrm{SCN}$ aqueous solution. Carbon plates and Silver/Silver chloride Electrode (SSE) were used as counter electrodes and a reference electrode, respectively. The initial potential was set at $-1.1 \mathrm{~V}$ vs. SSE, and the potential was shifted $0.1 \mathrm{~V}$ to the negative direction every $24 \mathrm{~h}$. The hydrogen embrittlement test was continued until cracks propagated throughout the stretch-formed specimen. During the hydrogen embrittlement test, photos of the specimen surfaces on both sides were taken every 1 min using a couple of digital cameras to observe the crack initiation and propagation behaviors. Moreover, the current density was monitored using a data logger to monitor the change of the current density. After the hydrogen embrittlement test, the fracture surface was observed by means of a Scanning Electron Microscope (SEM).

Hydrogen analysis of the stretch-formed specimen after

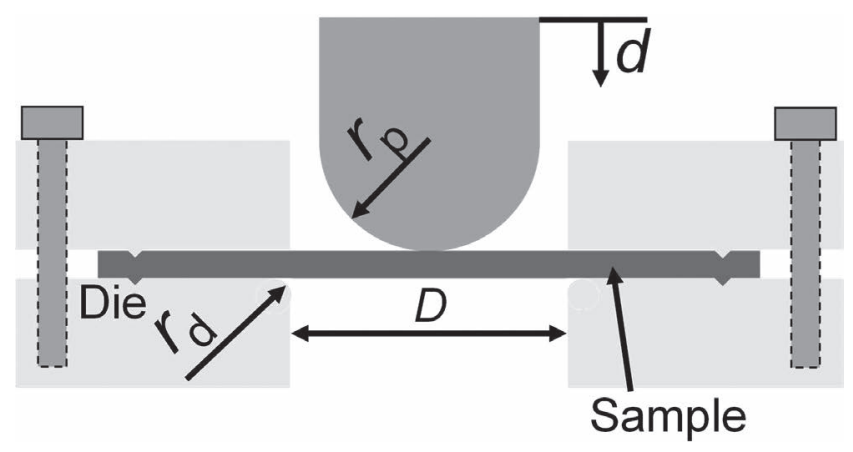

Fig. 1. Schematic view of the stretch-forming test unit used in this study. $r_{\mathrm{p}}$ : the radius of the hemisphere punch $(8.5$ $\mathrm{mm}), r_{\mathrm{d}}$ : the radius of the shoulder of the die $(1 \mathrm{~mm}), D$ : the inner diameter of the die's hole $(22 \mathrm{~mm}), d$ : the displacement of the punch $(4.2 \mathrm{~mm})$.

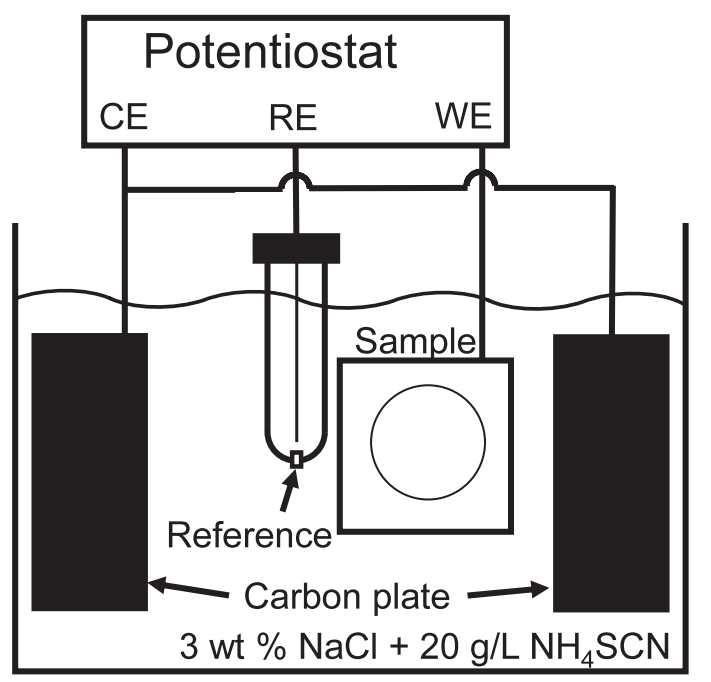

Fig. 2. Schematic view of the hydrogen embrittlement test unit $\mathrm{CE}, \mathrm{RE}$ and WE are counter, reference and working electrodes, respectively. 
hydrogen charging under the same condition as mentioned above was carried out. Samples with a size of $5 \mathrm{~mm} \times 5$ $\mathrm{mm}$ for hydrogen analysis were cut from 4 places from the top to the plain of the stretch-formed specimen as shown in Fig. 3. The hydrogen content in each sample was analyzed by means of a Thermal Desorption Spectrometer (TDS) (R-Dec Co., Ltd.) equipped with a quadrupole mass spectrometer. The specimen was heated from room temperature to $800^{\circ} \mathrm{C}$ at a heating rate of $100^{\circ} \mathrm{C} \mathrm{h}^{-1}$. In this study, the content of hydrogen desorbed from room temperature to $300^{\circ} \mathrm{C}$ was defined as a diffusible hydrogen content.

The residual stress distribution in the stretch-formed specimen was measured by means of synchrotron X-ray diffraction at beamline BL14B1 in SPring-8, using white $\mathrm{X}$-rays and a germanium semiconductor detector. The X-rays were shaped into $50 \mu \mathrm{m}$ in height and $300 \mu \mathrm{m}$ in width by a set of slits at an incident side and X-rays penetrated through the sample was limited by a collimator of 50-200 $\mu \mathrm{m}$ and a slit of $500 \mu \mathrm{m}$. The diffraction angle of the detector was set at $10^{\circ}$. The specimen was fixed on an $\mathrm{XYZ}$ stage and diffraction data were obtained at 3 positions in the thickness direction which were at the center and near the surfaces of both impression and depression sides of the stretch-formed specimen. The stresses in the radial and circumferential directions were measured from the top to the plain of the stretch-formed specimen every $1 \mathrm{~mm}$ to map the stress distributions. From the energy spectrum obtained by the X-ray diffraction analysis, the peak of $\alpha \mathrm{Fe} 321$ lattice plane was approximated by using a Gaussian function. The lattice spacing $(d)$ was calculated from the peak shift, and the stress was estimated from the elastic strain $\left(\varepsilon_{\mathrm{e}}\right)$, which can be obtained from the change in the lattice spacing using the following equation,

$$
\varepsilon_{\mathrm{e}}=\left(d-d_{0}\right) / d_{0}
$$

in which $d_{0}$ represents the lattice spacing of the as-heat-treated (non-stretch-formed) specimen and $d$ represents the lattice spacing of a measurement point on the stretch-formed specimen. Stresses in the circumferential and radial directions were calculated from the $\varepsilon_{\mathrm{e}}$ and mapped. The stress was estimated from Hook's law using Young's modulus of iron for simplification although the sample exhibited plane stress.

Finite element method (FEM) analysis was conducted using Abaqus CAE to analyze the stress and plastic strain distributions in the stretch-formed specimen. An axisymmetric model was used for the FEM analysis. The true stress-strain curve shown in Fig. 4 and the mechanical properties obtained from tensile tests using a tensile specimen with a dimension of $10 \mathrm{~mm}$ in length, $3 \mathrm{~mm}$ in width and 1.0 $\mathrm{mm}$ in thickness of the parallel part at a strain rate of $1.67 \times$ $10^{-3} \mathrm{~s}^{-1}$ were used for the analysis. The non-contact digital video extensometer was used to measure the elongation during the tensile test. Elastic limit and Young's modulus were defined as $658 \mathrm{MPa}$ and $189 \mathrm{GPa}$, respectively, according to the true stress-strain curve. The stress-strain behavior at plastic strain region was fitted using the least square method following the Swift's law ${ }^{24)}$ to conduct the FEM analysis. 4 nodes element was used, and the mesh size and the total number of elements for the analysis were $25 \mu \mathrm{m} \times 25 \mu \mathrm{m}$ and 24253 , respectively. A friction coefficient between punch and die which contacted each other was 0.1 . The

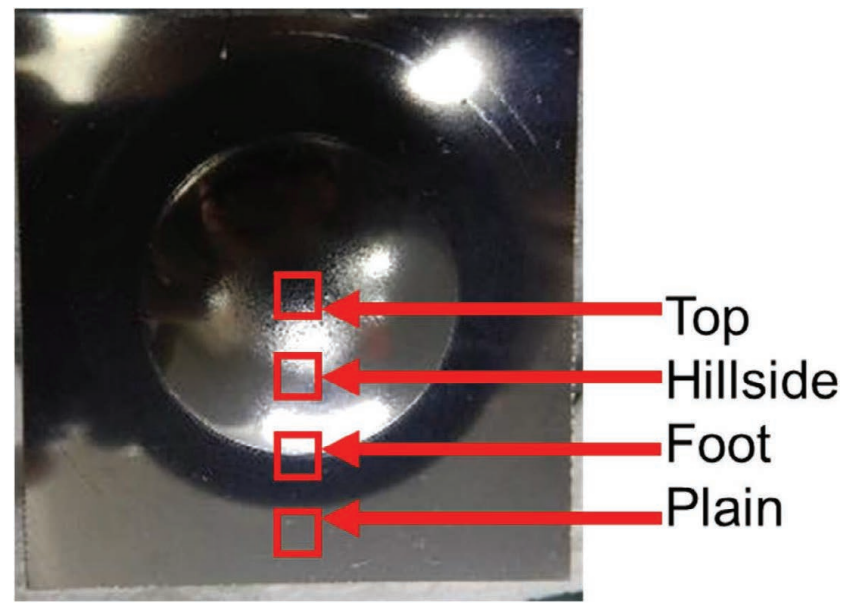

Fig. 3. The positions of samples cut out form a stretch-formed specimen for hydrogen thermal desorption measurements. Note that the photo in this figure is of an as-stretch-formed specimen though the samples were taken from a specimen after hydrogen embrittlement test having cracks. (Online version in color.)

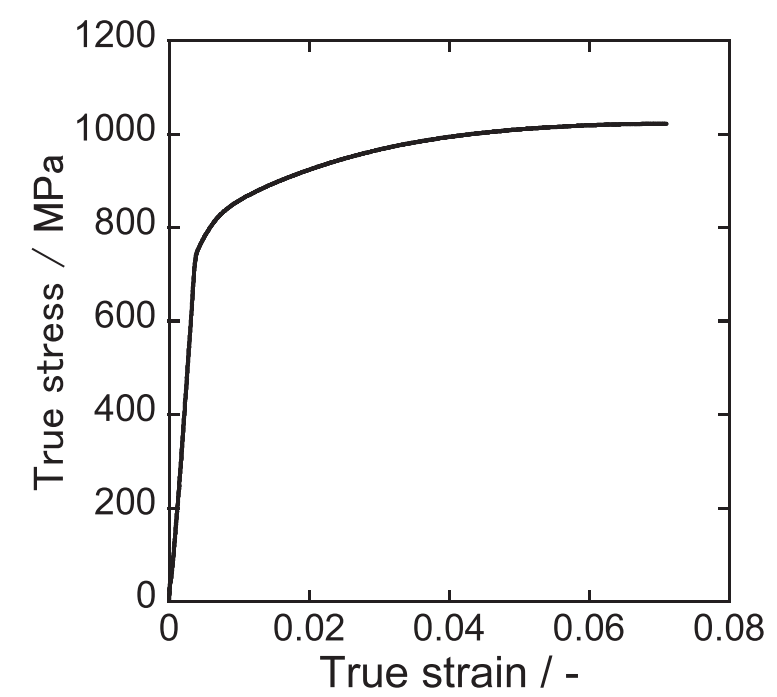

Fig. 4. True stress-strain curve of the tempered martensitic steel used in this study.

punch and die were defined as a rigid body. The stresses in the circumferential and radial directions, the equivalent plastic strain and hydrostatic stress were analyzed.

\section{Results and Discussion}

\subsection{Hydrogen Embrittlement Crack Initiation and Propagation Behaviors}

Figure 5 shows the change in the potential and current density as a function of time during the hydrogen embrittlement test of the tempered martensitic steel sheet specimen stretch-formed until the crosshead displacement of $4.2 \mathrm{~mm}$, and Fig. 6 shows the crack initiation and growth behaviors observed by the interval photographic method. The current density gradually decreased during the potentiostatic hydrogen charging at a potential of $-1.1 \mathrm{~V}$ for $24 \mathrm{~h}$, whereas the gradual decrease in the current density was temporarily stopped about 3 hours after changing the potential to -1.2 $\mathrm{V}$ (shown by the vertical dotted line in Fig. 5). According 


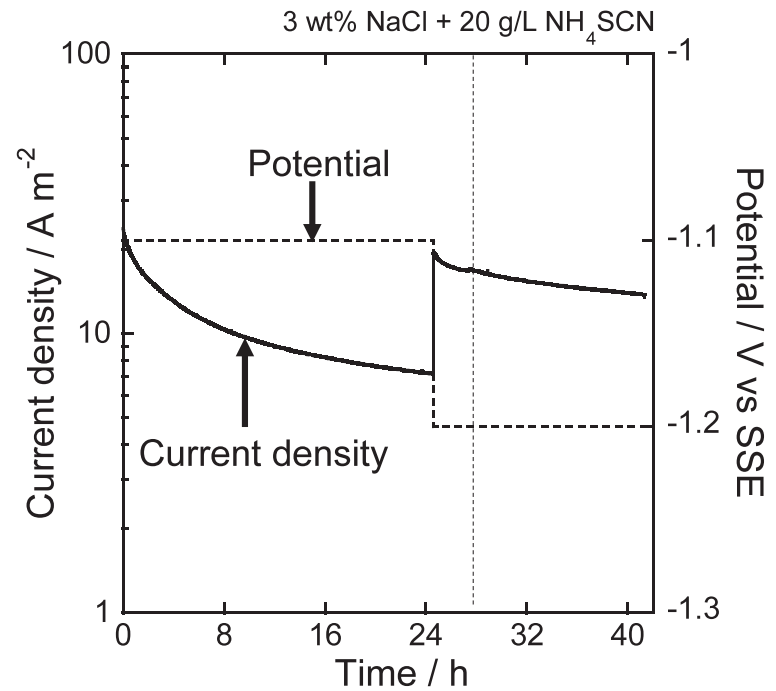

Fig. 5. Change in the potential and current density with time during hydrogen embrittlement test under potentiostatic hydrogen charging.

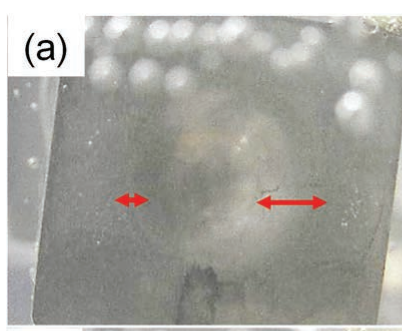

(b)

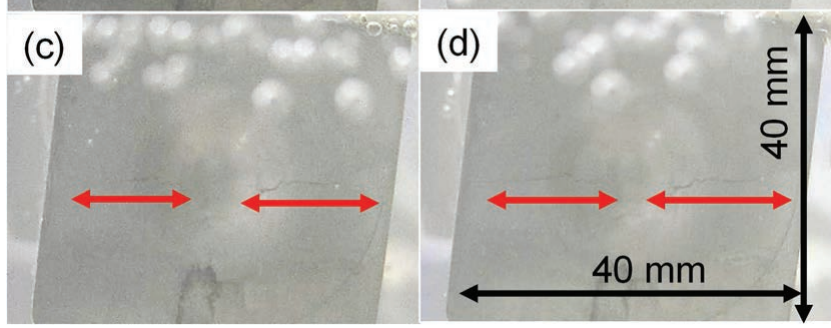

Fig. 6. Appearances of the crack initiation and propagation on the depression side of a stretch-formed specimen (a) 0 , (b) 2, (c) 4 and (d) $6 \mathrm{~h}$ after crack initiation. Red arrows indicate positions of the cracks. (Online version in color.)

to the interval photographic observations, cracking on the surface of the depression side occurred when the decrease in the current density was temporarily stopped (Fig. 6). Therefore, the crack opening and exposure of the newly formed bare metal surface might affect the change in the current density. The cracks initiated in the foot of the stretch-formed specimen and propagated along the radial direction. As seen in Fig. 6, two cracks were initiated almost simultaneously in face-symmetrical positions.

Figure 7 shows the appearances of the stretch-formed specimen after the hydrogen embrittlement test. Two cracks propagated along the radial direction and the cracks merged on the depression side of the top, whereas a ligament remained on the impression side surface. The same hydrogen embrittlement tests were carried out 4 times and the almost simultaneous initiations of two cracks on the face-symmetry positions were found to be reproducible. It is, therefore, speculated that the initiation of a crack affects the stress state especially in the face-symmetrical position
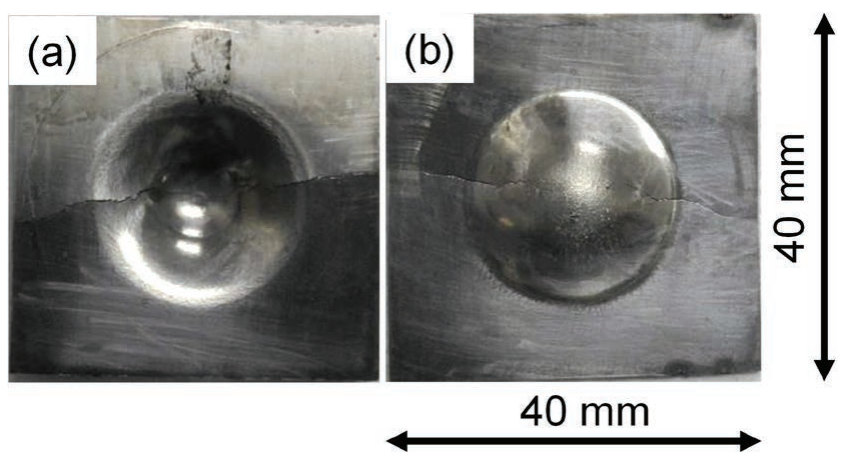

Fig. 7. Views of (a) the depression and (b) impression sides of the stretch-formed specimen after the hydrogen embrittlement test. (Online version in color.)

(a)

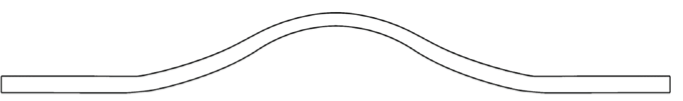

(b)

$3 \% \mathrm{NaCl}+20 \mathrm{~g} / \mathrm{L} \mathrm{NH}_{4} \mathrm{SCN}$

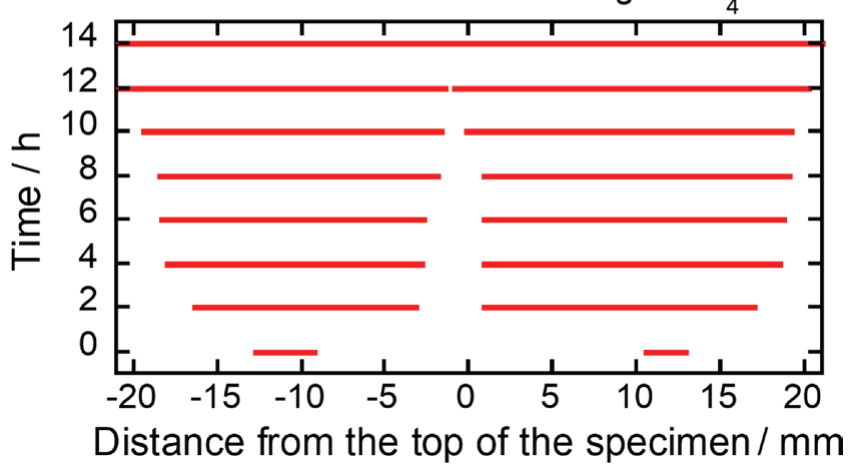

Fig. 8. (a) Schematic views of the cross section of the stretchformed specimen and (b) the crack growth with time. The cracks were observed from the depression side of the specimen. The red lines indicate positions where cracks existed. (Online version in color.)

and promotes the almost simultaneous initiation of the second crack.

Figure 8 shows the growth of cracks with time in the stretch-formed specimen during the hydrogen embrittlement test observed from the depression side. Both cracks initiated in the face-symmetrical positions in the foot where the specimen was contacted with the shoulder of the die during the stretch-forming and the cracks quickly propagated toward the top and the plain of the specimen in $2 \mathrm{~h}$ after the crack initiation. Then, the cracks further grew slowly to the top and the plain, and finally, the cracks propagated through the stretch-formed specimen and merged at the top after 14 h. SEM images of fracture surfaces in Fig. 9 show that the fracture surfaces exhibited a mixture of intergranular and quasi-cleavage fracture whole through the fracture surface, which is a typical hydrogen embrittlement morphology.

\subsection{Hydrogen Analysis}

Figure 10 shows the hydrogen desorption curves of the samples cut out from 4 positions of the stretch-formed specimen as shown in Fig. 3 after hydrogen charging in a $3 \mathrm{wt} \%$ $\mathrm{NaCl}+20 \mathrm{~g} \mathrm{~L}^{-1} \mathrm{NH}_{4} \mathrm{SCN}$ aqueous solution until cracks propagated through the specimen. The hydrogen desorption peaks of the specimens appeared around $90-100^{\circ} \mathrm{C}$, and 


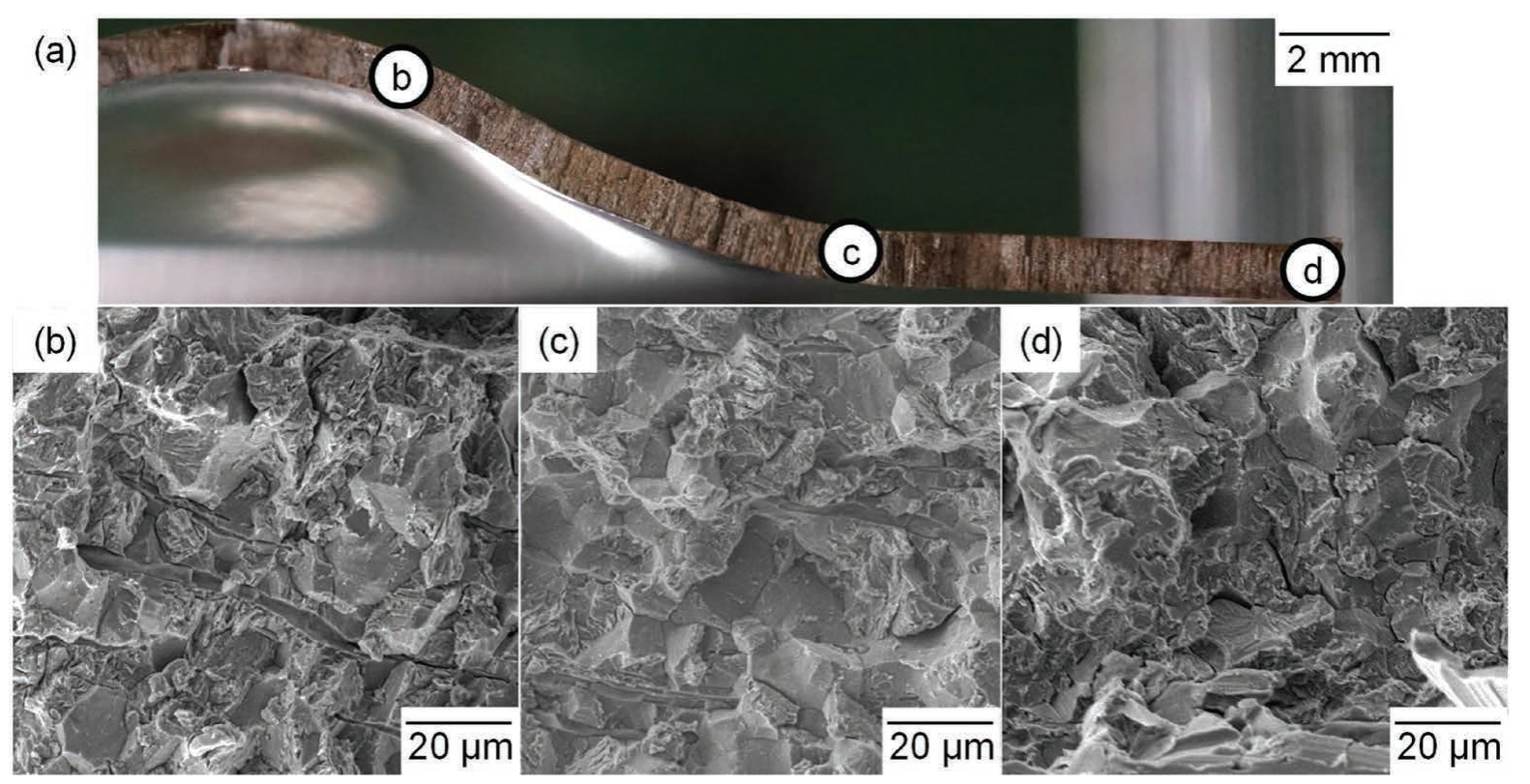

Fig. 9. (a) An optical image of the fractured specimen and SEM images of the fracture surfaces of the (b) top, (c) foot and (d) plain. (Online version in color.)

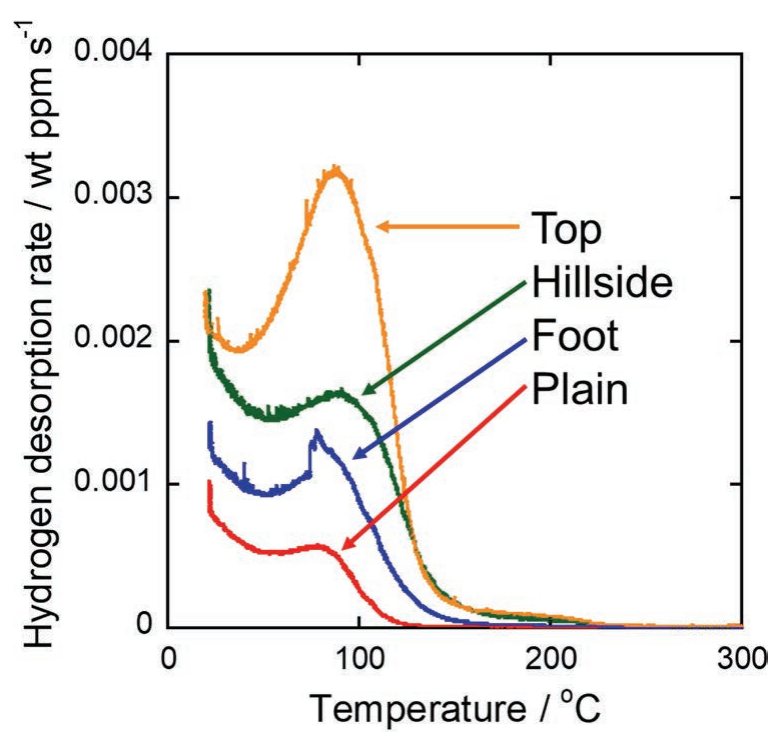

Fig. 10. Hydrogen evolution curves of the samples taken out form a hydrogen-charged stretch-formed specimen as shown in Fig. 3. (Online version in color.)

hydrogen was desorbed mostly below $150^{\circ} \mathrm{C}$. The height of the hydrogen desorption peak tended to decrease with distance from the top. Table 2 shows the diffusible hydrogen content of the samples obtained from hydrogen desorption curves in Fig. 10. The diffusible hydrogen content was the highest at the top and decreased with the distance from the top. The hydrogen content in the top was about 5 times as high as that in the plain. It has been reported that the increase of dislocation density due to the introduction of plastic strain leads to the increase of hydrogen content because the dislocations act as hydrogen trapping sites. ${ }^{23,25)}$ Therefore, it is considered that the difference of the diffusible hydrogen contents depending on the position was caused by the difference in the degree of plastic strain in the stretch-forming, namely, the density of hydrogen trapping sites. The distribution of the equivalent plastic strain
Table 2. Diffusible hydrogen content in samples taken from a hydrogen-charged stretch-formed specimen (weight ppm).

\begin{tabular}{cccc}
\hline Plain & Foot & Hillside & Top \\
\hline 1.89 & 3.91 & 6.52 & 9.82 \\
\hline
\end{tabular}

obtained by means of FEM will be discussed later.

The diffusible hydrogen content in the plane which had no apparent plastic strain was 1.89 weight ppm. In this study, the hydrogen charging solution contained relatively high concentration of $\mathrm{NH}_{4} \mathrm{SCN}$ to make cracking on the stretch-formed specimen of the $1000-\mathrm{MPa}$-class steel sheet. In contrast, the hydrogen contents in similar SCM435 steels without plastic strain corroded by outdoor exposure ${ }^{26,27)}$ and by cyclic corrosion test ${ }^{27,28)}$ were 0.2 weight ppm or lower. Under atmospheric corrosion condition in which hydrogen entry is not significant as compared to the hydrogen charging in the $\mathrm{NH}_{4} \mathrm{SCN}$ containing solution, hydrogen embrittlement cracking is not supposed to take place on the stretch-formed specimen used in this study.

\subsection{Measurement of Residual Stress Using Synchro- tron X-Ray Diffraction}

Figure 11 shows the distributions of the residual stresses in the radial and circumferential directions in the stretchformed specimen measured by means of synchrotron X-ray diffraction method at beamline BL14B1 in SPring-8. The stretch-formed specimen without hydrogen embrittlement test was used for the measurements. In the figure, the signs of "Center", "Depression" and "Impression" denote positions around the center in the thickness direction, just beneath the surface of depression and the impression sides, respectively. The tensile stress in the radial direction was observed on the center and impression side in the foot and plain, and on the depression side in the hillside, whereas the compressive stress was generated throughout the thickness around the top where the steel sheet was contacted with 

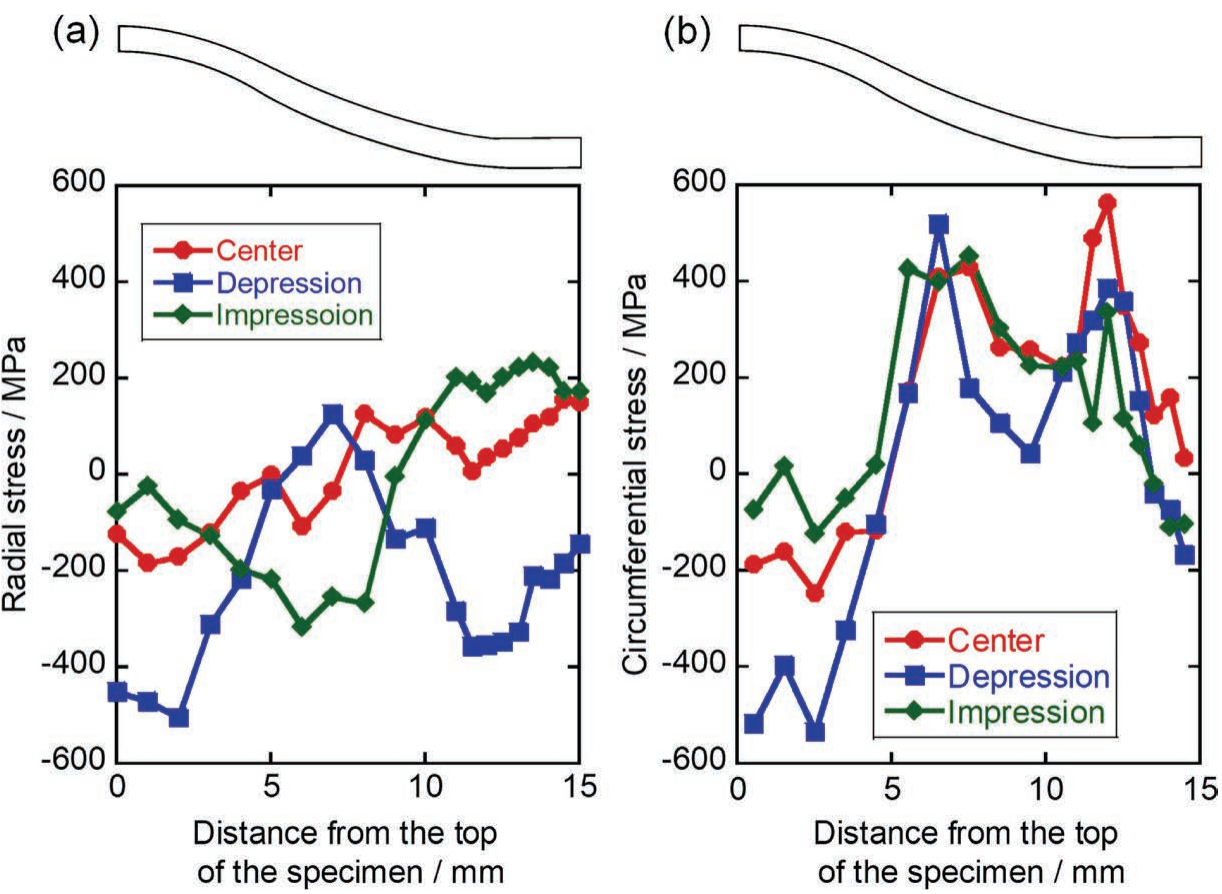

Fig. 11. Distributions of stresses in the (a) radial and (b) circumferential directions in the stretch-formed specimen measured by using synchrotron X-ray diffraction at SPring-8. (Online version in color.)

the punch during the stretch-forming. The depression side of the top showed the highest compressive stress. On the other hand, all the in-depth positions in the region from the hillside to the foot possessed relatively high tensile stress in the circumferential direction and showed two peaks, while compressive stress was seen around the top. Similar to the stress in the radial direction, the highest compressive stress in the circumferential direction was on the depression side. The comparison of the measured stress in Fig. 11 with the observed crack initiation sites shown in Fig. 8 indicates that the crack initiation sites corresponded to the foot where high tensile stress in the circumferential direction was generated. In addition, the crack growth direction, namely radial direction, demonstrates that the tensile stress in the circumferential direction was dominant to cause cracking. Although the top of the stretch-formed specimen possessed compressive stress, the cracks propagated to the top until the face-symmetrical cracks merged. This is because the stress state near the crack tip was changed probably owing to tensile plastic strain evolution in front of the crack tip and stress release at the crack wake during the crack growth.

\subsection{Analysis of Residual Stress and Plastic Strain Using Finite Element Calculations}

Figure 12 shows contour maps of the stress of circumferential and radial directions, hydrostatic stress and equivalent plastic strain in the stretch-formed specimen obtained by using Finite Element Method (FEM). The tensile stresses of both circumferential and radial directions exhibited the highest value in the foot, and these tensile stresses were also high on the depression side in the hillside. Around the top, compressive stresses in the circumferential and radial directions were obtained. Besides, the tensile stress in the circumferential direction tended to be higher than that in the radial direction. These analytical results are in good agreement with the results obtained from the synchrotron X-ray diffraction measurements described in the previous section. Corresponding to the relatively high tensile stresses in the circumferential and radial directions on the center in the thickness direction in the foot and on the depression side of the hillside, the hydrostatic stress showed negative value whose absolute value was high, in other words tensile triaxial stress was high, as shown in Fig. 12(c). The obtained equivalent strain was high around the top and the highest values were seen on the impression side. Reatively high strain was also located in the foot.

\subsection{Comparison of Results Obtained by Means of X-Ray Diffraction and FEM}

Figure 13 shows the comparison of the stresses in the radial and circumferential directions around the center in the thickness direction of the stretch-formed specimen analyzed by means of the synchrotron X-ray diffraction in SPring-8 and FEM. The hydrostatic stress obtained by means of FEM is also shown. Note that the stresses obtained by means of FEM shown in this figure is the average in the width of $300 \mu \mathrm{m}$ around the center in the thickness direction to compare with the stress obtained using the synchrotron X-ray diffraction which was measured in a gauge volume with a width of about $300 \mu \mathrm{m}$ in the thickness direction. The stress in the circumferential direction was higher than that in the radial direction in both cases of X-ray diffraction and FEM. Besides, the trend of the stress in the circumferential direction obtained by means of X-ray diffraction exhibited a good agreement with that of FEM, showing two tensile strain peaks in the foot and hillside. It can, therefore, be said that the stress distributions, at least that of the stress in the circumferential direction, are reasonable. The crack initiation site observed in the hydrogen embrittlement test corresponded to the highest peak of the tensile stress in the circumferential direction obtained by means of both FEM and X-ray diffraction analyses. The hydrostatic stress 
(a)

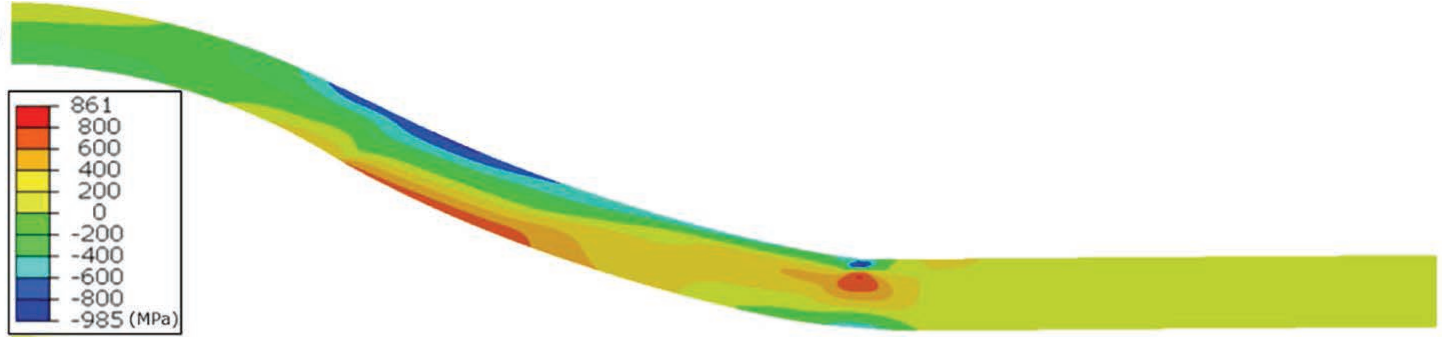

(b)

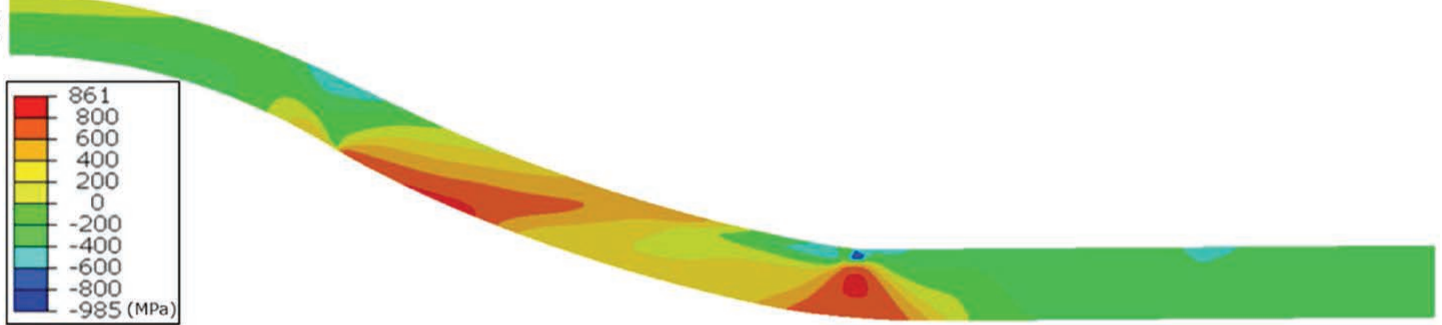

(c)

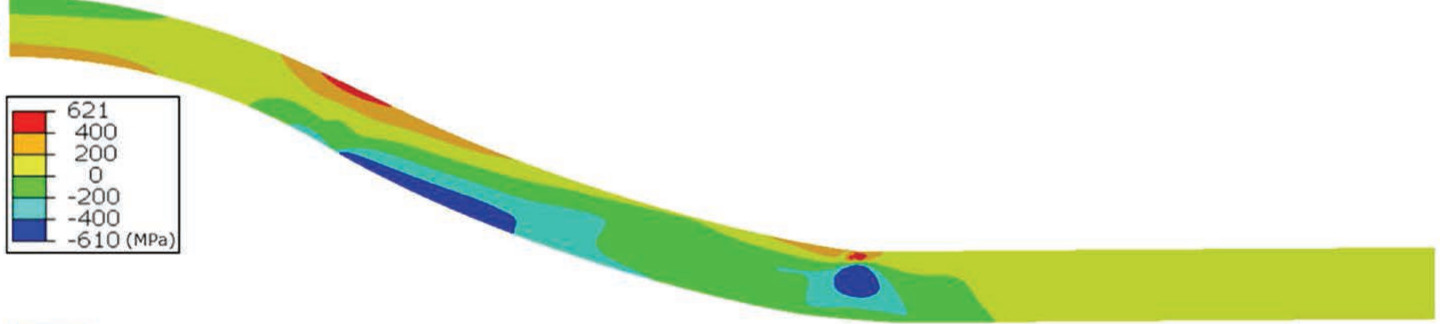

(d)

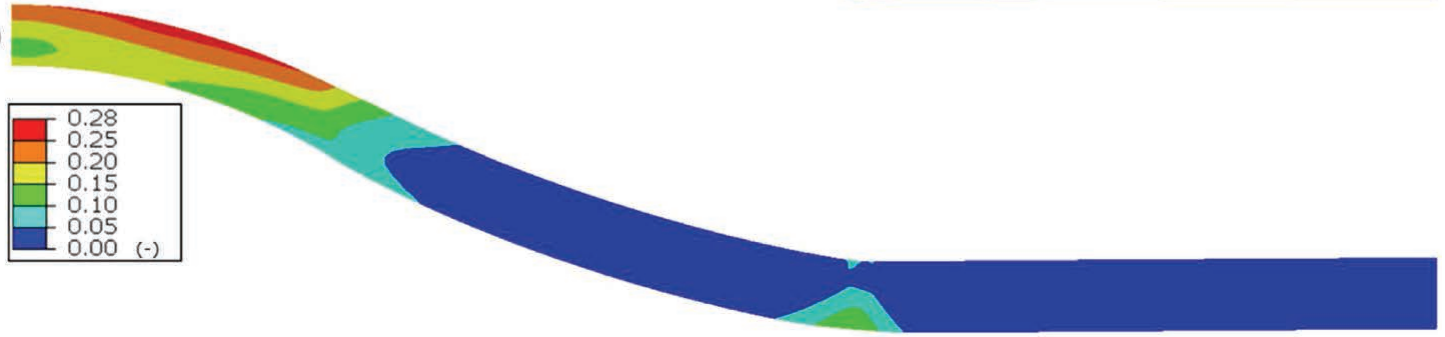

Fig. 12. Contour diagrams of (a) radial stress, (b) circumferential stress, (c) hydrostatic stress, and (d) equivalent plastic strain calculated by means of FEM. (Online version in color.)

obtained by means of FEM showed the minimum value in the foot corresponding to the tensile stresses in circumferential and radial directions.

\subsection{Effects of Residual Stress and Plastic Strain on Hydrogen Embrittlement}

Wang et al. and Akiyama et al. have carried out the tensile tests of hydrogen charged 1300 - and 1 500-MPa-grade circumferentially notched round bar specimens, ${ }^{1,5,29-32)}$ and have reported that intergranular fracture was initiated slightly inside from the notch root where the maximum principal stress showed the peak and the hydrogen accumulated due to hydrostatic stress. ${ }^{33)}$ In the present study, the tensile stress in the circumferential direction was the highest in the foot in the stretch-formed specimen according to the analyses by means of the X-ray diffraction and FEM, and the peak position corresponded to the crack initiation site. The higher stress in the circumferential direction than that in the radial direction presumably determined the direction of the cracks. Since the negative hydrostatic stress (tensile triaxial stress) contributes to the accumulation of hydrogen due to stress-induced hydrogen diffusion, ${ }^{4,21,22,30,31)}$ hydrogen concentration was considered high in the regions where the triaxial stress was high. According to the FEM results, high tensile triaxial stress (low hydrostatic stress) region was located in the foot, which is identical to the spot of the high tensile stresses in the circumferential and radial directions. The crack initiation in the foot indicates that the high tensile stress and accumulation of hydrogen due to the triaxial stress are determining factors for the crack initiation on the specimen.

The distribution of equivalent plastic strain obtained by means of FEM in Fig. 12(d) shows that the most strained region was the impression side of the top of the stretchformed specimen and that relatively high plastic strain was found in the foot as well. Though the in-depth position of the highest strain in the foot was not identical to that of the highest tensile stress in the circumferential direction, the plastic strain might also contribute to determining the position of the crack initiation site. It is known that deformed steels absorb more hydrogen because multiplied dislocations due to introduced plastic strain act as hydrogen trapping sites. The TDS analyses showed that the diffusible hydrogen content was the highest around the top and decreased with the distance from the top as shown in Fig. 10 and Table 2. These results indicate that the region with high plastic strain exhibited high diffusible hydrogen content. Though there is a spot in the foot where the plastic strain was relatively high, its contribution to the diffusible hydrogen content was not obvious probably because of the limited volume of the 
(a)

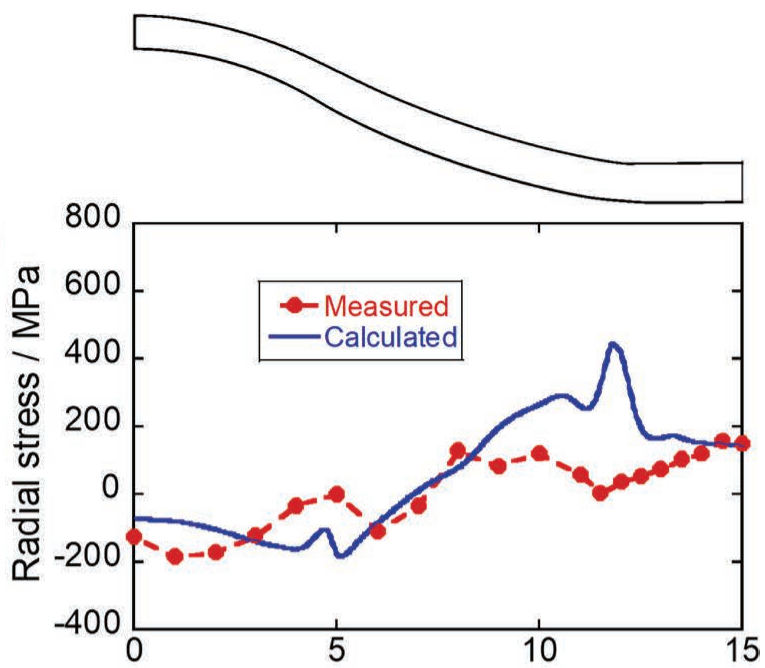

(b)

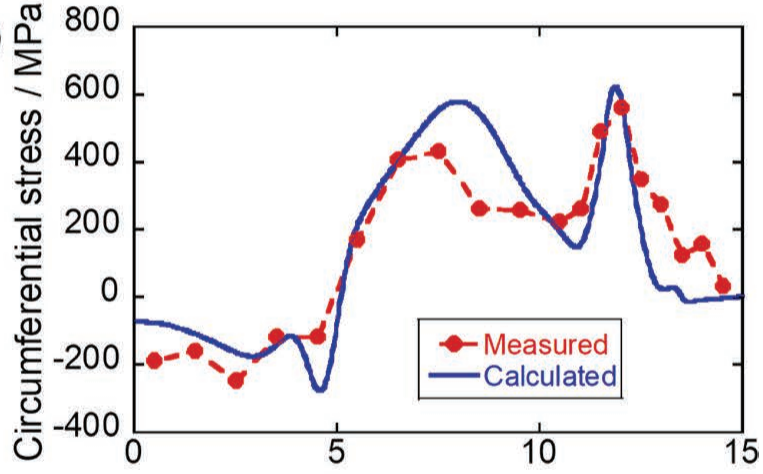

(c)

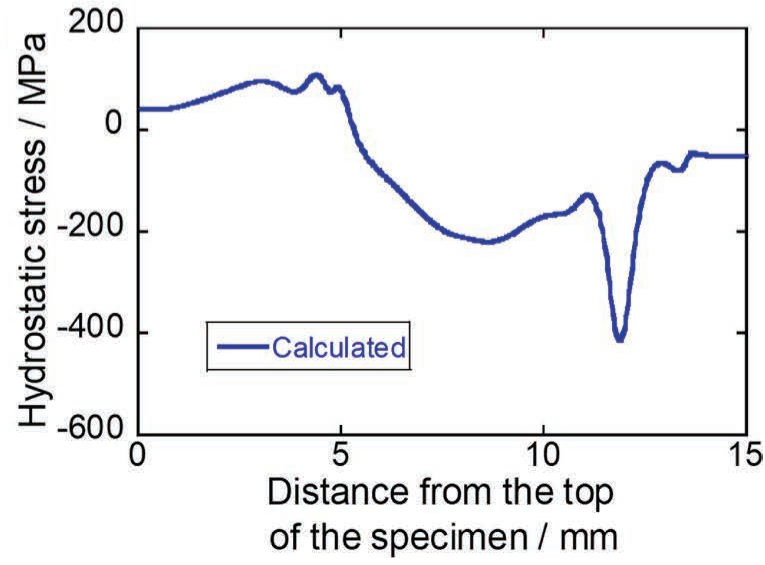

Fig. 13. (a) Radial stress, (b) circumferential stress, and (c) hydrostatic stress of the center in the thickness direction of a stretch-formed specimen. "Measured" and "Calculated" denote that the data were obtained by means of synchrotron X-ray diffraction and FEM, respectively. (Online version in color.)

highly strained region. Thus, the distribution of the diffusible hydrogen in the stretch-formed specimen depended on the plastic strain introduced by the stretch forming, but no direct correlation was seen with the crack initiation site. However, the high plastic strain in the foot might affect the cracking. Generally, the susceptibility to hydrogen embrittlement is increased with the strength level, and hardening due to plastic strain could increase the susceptibility in the strained region in the foot. Hence, the relatively high local strain in the foot might assist the crack initiation in addition to the local stress and accumulation of hydrogen.

In summary, it is suggested that the main factors of the occurrence of hydrogen embrittlement cracking in the foot of the stretch-formed specimen were the high residual tensile stress introduced by stretch forming and the accumulation of hydrogen due to the negative hydrostatic stress. In addition, the plastic strain was considered to supplementary affect the occurrence of hydrogen embrittlement cracking because of the increase in the hardness of steel in the foot of the stretch-formed specimen.

\section{Conclusions}

The effect of residual stress and plastic strain in a stretch-formed specimen of a tempered martensitic steel on its hydrogen embrittlement behavior was investigated. Residual stress distribution was measured by means of energy-dispersive method using white X-rays at BL14B1 in SPring-8. Moreover, the residual stress and plastic strain distributions in the stretch-formed specimens were analyzed by using FEM. The results are summarized as follows.

(1) Two cracks were initiated face-symmetrically in the foot of the impression of the stretch-formed specimen by hydrogen charging and were propagated along the radial direction showing a mixture of intergranular and quasicleavage fracture morphology.

(2) According to the residual stress distribution obtained by means of the XRD and FEM analyses, the tensile stress in the circumferential direction was the highest in the foot. The position with the maximum circumferential stress showed a good agreement with the crack initiation site, indicating that the stress is the determining factor for cracking. The stress in the circumferential direction tended to be higher than the stress in the radial direction. This is responsible for the crack initiation and propagation along the radial direction.

(3) The triaxial stress obtained by means of FEM was also high in the foot, which presumably caused the accumulation of diffusible hydrogen. This hydrogen accumulation is an additional determining factor for cracking.

(4) The diffusible hydrogen content at the top was the highest corresponding to the highest plastic strain due to the stretch forming. The diffusible hydrogen content measured by means of TDS increased with the plastic strain obtained by means of FEM analysis, though there was no direct correlation with the crack initiation site. The relatively high strain in the foot might assist the crack initiation due to hardening enhancing susceptibility to hydrogen embrittlement.

\section{Acknowledgment}

This work was supported by JSPS KAKENHI Grant-in-Aid for Scientific Research on Innovative Areas "Hydrogenomics", No. JP18H05513 and JP18H05514. Residual stress analyses using synchrotron X-ray radiation at SPring-8 were supported by the QST Advanced Characterization Nanotechnology Platform under the remit of "Nanotechnology Platform" of the Ministry of Education, Culture, Sports, Science and Technology (MEXT), Japan (Proposal Nos. A-17-QS-0024, A-18-QS-0011 and A-19-QS-0034). The synchrotron radiation experiments were performed using a QST experimental station at QST (JAEA) beamline BL14B1, SPring-8, with the approval of the Japan Synchrotron Radiation Research Institute (JASRI) (Proposal Nos. 2017B3681, 2018A3681 and 2019B3681). 
This work was also supported by ISIJ research group of "Corrosion-Induced Hydrogen Absorption to Steels" financially and the steel used in this study was provided from the group.

\section{REFERENCES}

1) E. Akiyama: ISIJ Int., 52 (2012), 307. https://doi.org/10.2355/ isijinternational.52.307

2) T. Tarui and S. Yamasaki: Tetsu-to-Hagané, 88 (2002), 612 (in Japanese). https://doi.org/10.2355/tetsutohagane1955.88.10 612

3) S. Yamasaki and T. Takahashi: Tetsu-to-Hagané, 83 (1997), 454 (in Japanese). https://doi.org/10.2355/tetsutohagane1955.83.7_454

4) S. Takagi, T. Inoue, T. Hara, M. Hayakawa, K. Tsuzaki and T. Takahashi: Tetsu-to-Hagané, 86 (2000), 689 (in Japanese). https:// doi.org/10.2355/tetsutohagane1955.86.10_689

5) M. Wang, E. Akiyama and K. Tsuzaki: Mater. Sci. Eng. A, 398 (2005), 37. https://doi.org/10.1016/j.msea.2005.03.008

6) M. Wang, E. Akiyama and K. Tsuzaki: Corros. Sci., 49 (2007), 4081. https://doi.org/10.1016/j.corsci.2007.03.038

7) Y. Hagihara, C. Ito, N. Hisamori, H. Suzuki, K. Takai and E. Akiyama: Tetsu-to-Hagané, 94 (2008), 215 (in Japanese). https://doi. org/10.2355/tetsutohagane.94.215

8) Y. Hagihara, T. Shobu, N. Hisamori, H. Suzuki, K. Takai and K. Hirai: Tetsu-to-Hagané, 97 (2011), 143 (in Japanese). https://doi. org/10.2355/tetsutohagane.97.143

9) Y. Hagihara, T. Oba, N. Hisamori, H. Suzuki and K. Takai: Tetsuto-Hagané, 97 (2011), 623 (in Japanese). https://doi.org/10.2355/ tetsutohagane.97.623

10) Y. Hagihara: ISIJ Int., 52 (2012), 292. https://doi.org/10.2355/ isijinternational.52.292

11) K. Takashima, Y. Yoshioka, K. Yokoyama and Y. Funakawa: ISIJ Int., 58 (2018), 173. https://doi.org/10.2355/isijinternational. ISIJINT-2017-315

12) T. Kumamoto, M. Koyama, K. Sato and K. Tsuzaki: Mater. Trans., 60 (2019), 2368. https://doi.org/10.2320/matertrans.MT-M2019196

13) T. Depover, E. Wallaert and K. Verbeken: Mater. Sci. Eng. A, 649 (2016), 201. https://doi.org/10.1016/j.msea.2015.09.124

14) T. Hojo, K. Sugimoto, Y. Mukai and S. Ikeda: ISIJ Int., 48 (2008), 824. https://doi.org/10.2355/isijinternational.48.824

15) T. Hojo, K. Chanvichitkul, H. Waki, F. Nishimura and E. Akiyama: Proced. Manuf., 15 (2018), 1581. https://doi.org/10.1016/j. promfg.2018.07.309

16) A. Laureys, T. Depover and K. Verbeken: Mater. Sci. Eng. A, 739 (2019), 437. https://doi.org/10.1016/j.msea.2018.10.072

17) T. Hojo, J. Kobayashi, K. Sugimoto, A. Nagasaka and E. Akiyama: Metals, 10 (2020), 6. https://doi.org/10.3390/met10010006

18) J. A. Ronevich, B. C. De Cooman, J. G. Speer, E. D. Moor and D. K. Matlock: Metall. Mater. Trans. A, 43 (2012), 2293. https://doi. org/10.1007/s11661-011-1075-3

19) S. J. Lee, J. A. Ronevich, G. Krauss and D. K. Matlock: ISIJ Int., 50 (2010), 294. https://doi.org/10.2355/isijinternational.50.294

20) Y. Momotani, A. Shibata, D. Terada and N. Tsuji: Int. J. Hydrog. Energy, 42 (2017), 3371. https://doi.org/10.1016/j. ijhydene.2016.09.188

21) Y. Toji, S. Takagi, M. Yoshino, K. Hasegawa and Y. Tanaka: Tetsuto-Hagané, 95 (2009), 887 (in Japanese). https://doi.org/10.2355/ tetsutohagane.95.887

22) M. Yoshino, Y. Toji, S. Takagi and K. Hasegawa: Tetsu-to-Hagané, 99 (2013), 302 (in Japanese). https://doi.org/10.2355/tetsutohagane.99.302

23) Y. Shibayama, T. Hojo and E. Akiyama: Tetsu-to-Hagané, 105 (2019), 927 (in Japanese). https://doi.org/10.2355/tetsutohagane. TETSU-2019-036

24) N. Tsuchida, S. Harjo, T. Ohnuki and Y. Tomota: Tetsu-toHagané, 100 (2014), 1191 (in Japanese). http://doi.org/10.2355/ tetsutohagane.100.1191

$25)$ B. Kumai, T. Hojo, M. Koyama, E. Akiyama, H. Waki and A. Nagasaka: Int. J. Hydrog. Energy, 45 (2020), 27920. https://doi. org/10.1016/j.ijhydene.2020.07.036

26) E. Akiyama, K. Matsukado, S. Li and K. Tsuzaki: Appl. Surf. Sci., 257 (2011), 8275. http://doi.org/10.1016/j.apsusc.2011.03.037

27) E. Akiyama, S. Li, T. Shinohara, Z. Zhang and K. Tsuzaki: Electrochim. Acta, 56 (2011), 1799. https://doi.org/10.1016/j.electacta.2010.09.043

28) S. Li, Z. Zhang, E. Akiyama, K. Tsuzaki and B. Zhang: Corros. Sci., 52 (2010), 1660. https://doi.org/10.1016/j.corsci.2010.02.005

29) M. Wang, E. Akiyama and K. Tsuzaki: Mater. Sci. Technol., 22 (2006), 167. https://doi.org/10.1179/174328406X86191

30) E. Akiyama, M. Wang, S. Li, Z. Zhang, Y. Kimura, N. Uno and K. Tsuzaki: Metall. Mater. Trans. A, 44 (2013), 1290. https://doi. org/10.1007/s11661-012-1403-2

31) M. Wang, E. Akiyama and K. Tsuzaki: Mater. Sci. Technol., 22 (2006), 167. https://doi.org/10.1179/174328406X86191

32) M. Wang, E. Akiyama and K. Tsuzaki: Scr. Mater., 52 (2005), 403. https://doi.org/10.1016/j.scriptamat.2004.10.023

33) R. A. Oriani: Acta Metall., 18 (1970), 147. https://doi. org/10.1016/0001-6160(70)90078-7 